\title{
Determination of Chlorfenvinphos in Soils by Microwave-Assisted Extraction and Stripping Voltammetry with an Ultramicroelectrode
}

\author{
Simone Morais, Oriza Tavares, Paula Paíga, and \\ Cristina Delerue-Matos
}

\begin{abstract}
A methodology for the determination of the pesticide chlorfenvinphos by microwave-assisted solvent extraction and square-wave cathodic stripping voltammetry at a mercury film ultramicroelectrode in soil samples is proposed. Optimization of microwave solvent extraction performed with two soils, selected for having significantly different properties, indicated that the optimum solvent for extracting chlorfenvinphos is hexane-acetone $(1: 1, \mathrm{v} / \mathrm{v})$. The voltammetric procedure is based on controlled adsorptive accumulation of the insecticide at the potential of -0.60 $\mathrm{V}$ (vs. $\mathrm{Ag} / \mathrm{AgCl}$ ) in the presence of Britton-Robinson buffer ( $\mathrm{pH}$ 6.2). The detection limit obtained for a $10 \mathrm{~s}$ collection time was $3.0 \times 10^{-8} \mathrm{~mol} \mathrm{l}^{-1}$. The validity of the developed methodology was assessed by recovery experiments at the $0.100 \mathrm{\mu g} \mathrm{g}^{-1}$ level. The average recoveries and standard deviations for the global procedure reached by MASE-square-wave voltam-metry were $90.2 \pm 2.8 \%$ and $92.1 \pm 3.4 \%$ for type I (soil rich in organic matter) and type II (sandy soil) samples, respectively. These results are in accordance to the expected values which show that the method has a good accuracy.
\end{abstract}

Keywords: Chlorfenvinphos, mercury film ultramicroelectrode, microwave-assisted solvent extraction, soils 


\section{INTRODUCTION}

Organophosphorus compounds are one of the most important classes of insecticides. There are a number of characteristics of these pesticides, including their persistence, degradation and elimination, genetic effects on diverse organisms, and effects on people's health that are of social and scientific interest (Manzanilla-Cano et al. 2001). Chlorfenvinphos (I) (2-chloro-1(2,4-dichlorophenyl) vinyl diethyl phosphate) belongs to this group and it is a systemic and general insecticide registered for use in both agricultural and veterinary situations (Tomlin 1997; http://www.eco-usa.net/toxics/chlorfen. shtml). As an agricultural chemical, it is important for insect control in pastures, for potatoes and mushrooms. As a veterinary chemical it is registered as an ectoparasite treatment for livestock. Chlorfenvinphos may also be used in public health programs especially against mosquito larvae (Tomlin 1997; http:// www.eco-usa.net/toxics/chlorfen.shtml).<smiles>CCOP(=O)(OCC)OC(=CCl)c1ccc(Cl)cc1Cl</smiles>

(I)

The largely preferred analytical approaches to the determination of chlorfenvinphos are based on a separation by gas (Russo et al. 2002; USEPA 1994) or liquid chromatography (Jansson et al. 2004; Uygun 1997) coupled with several kinds of detectors. In general, time-consuming preconcentration steps are needed to determine the analyte at ppb levels for both the instrumental techniques. Indeed, in the industrialized countries gas chromatography (GC) and/or liquid chromatography and mass spectrometry (LC-MS) methods are often the techniques of choice for identification and determination of pesticides. However, in the developing countries the mass spectroscopy (MS) instrumentation is financially prohibitive for comparable wide usage, yet the need for pesticide analysis is arguably even greater than for the industrialized nations because of the agrarian basis of the former countries. Thus, development of reliable and fit-for-purpose methods of analysis for pesticides with the use of simple and relatively inexpensive instrumentation is an appropriate objective to strive for. Literature shows that electrochemical methods have also been applied for the trace analysis of organophosphorus pesticides (El-Shahawi and Kamal 1998; Garrido et al. 2004; Ni et al. 2004; Manisankar et al. 2005). Most of them rely on polarographic and voltammetric procedures at mercury conventional electrodes (Garrido et al. 2004). Owing to the inherent advantages possessed by electrodes of small dimensions and to the drastic reduction in 
the amount of mercury consummated, the use of mercury film ultramicroelectrodes (MFU) has become widespread in electroanalysis (Baldo et al. 2002; Morais et al. 2005). To the best of our knowledge, no report exists on the use of the latter electrodes for the determination of chlorfenvinphos.

In the analytical studies of pesticides from soil samples, the extraction procedure before their quantitative determination is as important as the instrumental technique. Extensive sample handling is usually required. The use of microwave-assisted solvent extraction (MASE) has many advantages over other classical techniques (Soxhlet, sonication or shake-flask extraction) like reduction of extraction time and of solvent consumption, as well as, the possibility of running multiple samples (Eskilsson and Bjorklund 2000). The purpose of this work was to study the applicability of MASE coupled to stripping voltammetry performed by a MFU in order to obtain a simple, fast and highly sensitive procedure for analysis of chlorfenvinphos in soils.

\section{EXPERIMENTAL}

\section{Reagents}

Stock standard solutions of chlorfenvinphos (Riedel- de Haën, Germany; certified purity higher than 97.7\%) were freshly prepared in ethanol or in acetonitrile for high-performance liquid chromatography (HPLC) assays. For HPLC calibration plot standards, subsequent dilutions were made with acetonitrile and water in order to obtain a final ratio of 50:50, v/v (composition of the mixture selected to perform the isocratic elution). Solutions were stored at $4{ }^{\circ} \mathrm{C}$ and protected from light.

The mercury deposition solution was a deoxygenated solution containing $1.0 \mathrm{~mol} \mathrm{l}^{-1}$ potassium nitrate plus $5.7 \times 10^{-3} \mathrm{~mol}^{-1}$ mercury (II) nitrate and $0.5 \%$ (v/v) nitric acid (65\%) (Morais et al. 2000, 2003).

The supporting electrolyte was the Britton-Robinson buffer at $\mathrm{pH}=6.2$ (Mongay and Martín 1977) prepared with $4.0 \times 10^{-2} \mathrm{~mol} \mathrm{l}^{-1}$ acetic acid, $4.0 \times 10^{-2} \mathrm{~mol}^{-1}$ phosphoric acid, and $4.0 \times 10^{-2} \mathrm{~mol}^{-1}$ boric acid. For $\mathrm{pH}$ studies, required $\mathrm{pH}$ values were adjusted by addition of $0.5 \mathrm{~mol}^{-1}$ or $5.0 \mathrm{~mol}^{-1}$ hydrochloride acid or sodium hydroxide.

Acetonitrile, dichloromethane, methanol, hexane, and acetone were HPLC grade (Merck, Germany). All other reagents used were of analytical grade (Merck). Deionized and triply distilled water was used for preparing all solutions.

\section{Apparatus}

An AUTOLAB potentiostat/galvanostat model PSTAT 10 coupled with an ECD Module from EcoChemie controlled by a PC, through the Model 
GPES3 software, was used for all electrochemical measurements. The voltammetric studies were performed with a working MFU using an $\mathrm{Ag} / \mathrm{AgCl}$ / $3.0 \mathrm{~mol}^{-1}$ potassium chloride reference electrode (to which all the potential values are referred) and a cylindrical carbon counter electrode. Electrical connections were made with low noise coaxial cables and the electrochemical system was placed inside a thick-walled aluminium Faraday cage.

For comparison of measurements in the determination of chlorfenvinphos in soil samples, a HPLC system (Sykam 1210 liquid chromatograph) equipped with a $3200 \mathrm{UV} / \mathrm{VIS}$ detector selected to $203 \mathrm{~nm}$ and connected to a computing integrator with a chromatography data station (PRIME 2.2.6) was used. The system had an injection valve with a $20 \mu$ l loop. The chromatographic separations were done on an ET Nucleosil $\mathrm{C}_{18}$ column $(250 \times 4.6 \mathrm{~mm} ; 5 \mu \mathrm{m}$ particle size) from Macherey-Nagel. Isocratic elution was accomplished at a flow-rate of $1.0 \mathrm{ml} \mathrm{min}^{-1}$.

Microwave assisted extractions were performed with a MARS-X, $1500 \mathrm{~W}$ microwave accelerated reaction system for extraction (CEM, Mathews, NC) configured with a 14 position carousel. During operation, both temperature and pressure were monitored in a single vessel. Magnetic stirring in each extraction vessel and a sensor registering the solvent leaks in the interior of the microwave oven were also used.

\section{Preparation of the Spiked Soil Samples}

Two different soils; type I- $\mathrm{pH}$ 5.8, organic matter content $8.4 \%$, water content $1.8 \%$ and type II: $\mathrm{pH} 7.8$, organic matter content $2.2 \%$, water content $0.17 \%$ (Hesse 1972), were collected from two fields in Chaves region (in the north of Portugal) and were thoroughly mixed to ensure homogeneity. After air drying and sieving to a grain size of $2 \mathrm{~mm}$, the soils samples were stored at $4^{\circ} \mathrm{C}$.

For recovery determination assays, the spiked soil samples were prepared by adding to a portion of $5 \pm 0.1 \mathrm{~g}$ of soil, $1 \mathrm{ml}$ of $1.43 \times 10^{-5} \mathrm{~mol} \mathrm{l}^{-1}$ (spiked level $1.0 \mu \mathrm{g} \mathrm{g}^{-1}$ ) or $1.43 \times 10^{-6} \mathrm{~mol} \mathrm{l}^{-1}\left(0.1 \mu \mathrm{g} \mathrm{g}^{-1}\right)$ chlorfenvinphos standard solutions (for blanks, $1 \mathrm{ml}$ of pure ethanol was added). The samples were allowed to stand $24 \mathrm{~h}$ to air dry and were extracted by MASE thereafter.

\section{Microwave-Assisted Solvent Extraction of Soil Samples}

The spiked $(n=6)$ and blank soil samples $(n=1)$ were transferred quantitatively to the glass extraction vessels. After adding to each sample $20 \mathrm{ml}$ of the tested MASE solvent, the vessels were closed. Two solvents were selected, namely, hexane-acetone $(1: 1, \mathrm{v} / \mathrm{v})$ and dichloromethane-methanol $(90: 10$, $\mathrm{v} / \mathrm{v})$. The operational parameters of the MASE apparatus applied were magnetron power $100 \%$, time to reach settings $10 \mathrm{~min}$, extraction temperature 
$100^{\circ} \mathrm{C}$, extraction duration $10 \mathrm{~min}$, medium speed stirring, and maximum vessel pressure cut off 200 psi. After the extraction, the vessels were allowed to cool to room temperature before they were opened. The supernatants were filtered through a Whatman No. 42 filter paper, which were then evaporated to dryness under a gentle stream of nitrogen. For recovery studies, immediately before analysis, the residues were redissolved by the addition of $1 \mathrm{ml}$ of HPLC eluent (twenty times preconcentration) or $20 \mathrm{ml}$ of the Britton-Robinson buffer $(\mathrm{pH}=6.2)$

\section{Voltammetric Procedure}

The working MFU was prepared by electrodeposition of a mercury film onto the gold ultramicrodisk (radius $=12.5 \times 10^{-6} \mathrm{~m}$; purchased from the Department of Chemistry of the University of Southampton) by the application of a constant potential of $0.00 \mathrm{~V}$ during a deposition time of $60 \mathrm{~s}$ from the mercury deposition solution (Morais et al. 2000, 2003). The MFU was removed, rinsed with deionised and triply distilled water and inserted in the solution to be analyzed.

For the optimization studies, the test solutions were microwave-assisted solvent blank extracts of type I matrix redissolved with the supporting electrolyte, fortified with the insecticide standard and purged with nitrogen $(99.99 \%$ from LINDE Portugal) for $15 \mathrm{~min}$. The preconcentration was accomplished in quiescent solutions at the optimal potential of $-0.60 \mathrm{~V}$ during a certain deposition time. Following the cathodic potential scan, a conditioning potential of $-1.6 \mathrm{~V}$ was applied to the MFU during $10 \mathrm{~s}$. The square-wave parameters used (except where otherwise stated) were a frequency of $250 \mathrm{~Hz}$, amplitude of $20 \mathrm{mV}$ and a staircase step of $3 \mathrm{mV}$. The quantifications were achieved by the standard addition method.

\section{RESULTS AND DISCUSSION}

\section{Microwave-Assisted Solvent Extraction of Soil Samples}

First, sample pretreatment for two soils having considerable different properties (type I and II) was optimized. Because MASE is rather a new methodology, the combination of matrix/pesticide/solvent/time of extraction needs to be investigated. Validation of the proposed MASE procedure was performed by recovery studies (spiking of soil samples at the $1.0 \mu \mathrm{g} \mathrm{g}^{-1}$ level) using a classical HPLC with UV detection reported method (Uygun 1997). Using the referred experimental conditions (Uygun 1997), the retention time of chlorfenvinphos was $17.5 \mathrm{~min}$ and HPLC calibration curve was established between $8.17 \times 10^{-6} \mathrm{~mol} \mathrm{l}^{-1}$ and $1.0 \times 10^{-4} \mathrm{~mol} \mathrm{l}^{-1}$ $\left(\mathrm{A}=-252+5.40 \times 10^{8}\right.$ [chlorfenvinphos] $\left.\left(\mathrm{mol} \mathrm{l}^{-1}\right) ; \mathrm{r}=0.9996 ; n=7\right)$. 
Since extraction efficiency and selectivity are strongly affected by the solvent, this parameter was firstly optimized by testing two solvent mixtures, namely, hexane-acetone $(1: 1, \mathrm{v} / \mathrm{v})$ and dichloromethane-methanol $(90: 10, \mathrm{v} / \mathrm{v})$. The obtained results (Table 1) show that the process provides average recoveries higher than $95 \%$ for both solvent systems tested. Slightly higher recoveries were obtained from the sandy soil (type II), probably because it contains very little organic matter. Also, the hexane-acetone mixture yielded the clearest extracts although; all extracts were completely translucent avoiding the need for further cleanup. Taking these observations in consideration and that dichloromethane being environmentally more aggressive, the chosen solvent was hexane-acetone $(1: 1 ; \mathrm{v} / \mathrm{v})$. No other MASE parameter was optimized due to the very acceptable data reached with the first selected set of operational conditions (10 min to reach settings; $100 \%$ power of microwave unit; $5 \pm 0.1 \mathrm{~g}$ of soil; $\mathrm{T}=100^{\circ} \mathrm{C}$ during $10 \mathrm{~min}$; medium stirring).

The following described voltammetric optimization studies were performed in type I soil extract residues bearing in mind that the high organic matter content of this soil will generate the more adverse experimental conditions.

\section{Characterisation of the Electrochemical Process}

Although cyclic voltammetry has generally a much lower sensitivity as compared with square-wave voltammetry, it is often used to investigate the electrochemical behavior of compounds. Fig. 1 shows two successive cyclic voltammograms for $1.0 \times 10^{-6} \mathrm{~mol} \mathrm{l}^{-1}$ of chlorfenvinphos recorded at a scan rate of $250 \mathrm{mV} \mathrm{s}^{-1}$ after accumulation at $-0.60 \mathrm{~V}$ during $10 \mathrm{~s}$ before the first scan. A clearly defined cathodic peak that may be attributed to the reduction of the carbon-carbon double bond $(>\mathrm{C}=\mathrm{C}<$ ) present in chlorfenvinphos in a two-electron process (Garrido et al. 2004) is observed

Table 1. Chlorfenvinphos recoveries from $24 \mathrm{~h}$ spiked soil samples using MASE with two extraction solvents (spiked level $1.0 \mu \mathrm{g} \mathrm{g}^{-1}$ ). RSD-relative standard deviation; type I soil: $\mathrm{pH} 5.8$, organic matter content $8.4 \%$, water content $1.8 \%$; type II soil: $\mathrm{pH} 7.8$, organic matter content $2.2 \%$, water content $0.17 \%$

\begin{tabular}{lcc}
\hline Solvent & $\begin{array}{c}\text { Soil sample } \\
\text { type }\end{array}$ & $\begin{array}{c}\text { Recovery and } \\
\operatorname{RSD}(\%) n=6\end{array}$ \\
\hline Hexane-acetone $(1: 1 ; \mathrm{v} / \mathrm{v})$ & I & $95.7 \pm 2.9$ \\
Dichloromethane-methanol $(90: 10 ; \mathrm{v} / \mathrm{v})$ & II & $98.5 \pm 1.7$ \\
& I & $96.0 \pm 2.2$ \\
& II & $96.4 \pm 4.4$ \\
\hline
\end{tabular}




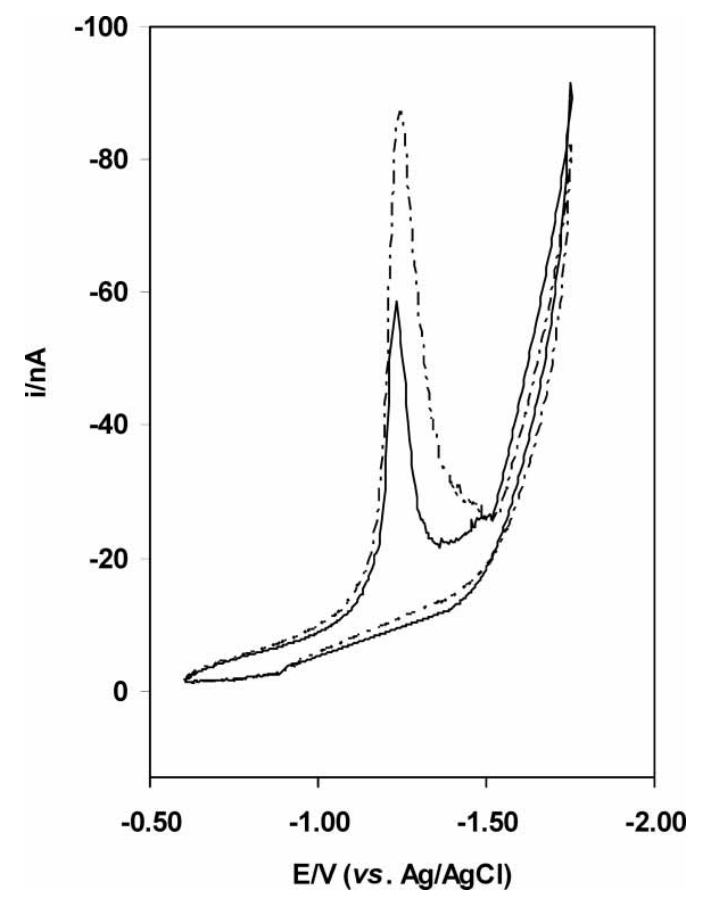

Figure 1. Successive (-- - first scan) cyclic voltammograms for a soil extract containing $1.0 \times 10^{-6} \mathrm{~mol}^{-1}$ of chlorfenvinphos $(\mathrm{pH}=6.2)$ after $10 \mathrm{~s}$ deposition at $-0.60 \mathrm{~V}$ for the first scan. Scan rate: $250 \mathrm{mV} \mathrm{s}^{-1}$. No accumulation was performed before the second scan.

at $\sim-1.2 \mathrm{~V}$. On the reverse scans, no anodic wave appears. The short preconcentration time applied results in a great enhancement of the peak intensity $(\sim 70 \%)$ as compared with the response obtained at the second scan performed without a deposition step (continuous line in Fig. 1; spontaneous accumulation of the insecticide occurs during scanning from $-0.60 \mathrm{~V}$ till the peak potential). Having regard to its molecular structure, chlorfenvinphos is rather hydrophobic compound and adsorption behavior at the MFU surface in aqueous medium is not surprising. Then, the sensitivity of the determination of the investigated organophosphorus pesticide can be increased by an adsorptive preconcentration step. In this study, the slope of the log chlorfenvinphos peak current against the square root of the scan rate yielded a straight line with a correlation coefficient of $0.997(n=12$; the scan rate was varied between $10 \mathrm{mV} \mathrm{s}^{-1}$ and $2000 \mathrm{mV} \mathrm{s}^{-1}$ ) and the peak potentials shifted to more negative values with increasing scan rate. Altogether, these observations are in agreement with the properties of a diffusion controlled irreversible electrochemical process as described by Bard and Faulkner (Bard and Faulkner 1980). 


\section{Optimization of Parameters for Chlorfenvinphos Detection}

Although, variation of the ionic strength and the type of electrolyte have a less pronounced effect in the analytical signal when ultramicroelectrodes are used (Montenegro et al. 1991), a wide range of possible supporting electrolytes were tested including potassium chloride, the Britton-Robinson buffer and a boric acid-sodium hydroxide buffer. The Britton Robinson buffer was found to be the most suitable medium since the voltammograms of the analyte in this buffer were well shaped and quite sensitive over a relatively wide $\mathrm{pH}$ range, 2.5-8.0. The dependence of the peak height on the $\mathrm{pH}$ of the Britton-Robinson buffer (between 2.5 and 10) has been shown in Fig. 2, with the maximum response found at $\mathrm{pH} 6-7.5$. For $\mathrm{pH}>8.0$, the peak current drops considerably probably due to the rapid hydrolysis of chlorfenvinphos that occurs in strongly alkaline solutions (Tomlin 1997). Also, in basic media, the reduction of $>\mathrm{C}=\mathrm{C}<$ group is not easily facilitated owing to the less availability of protons. Furthermore, a shift of the peak potential towards more negative values was observed as the $\mathrm{pH}$ increased, confirming the existence of a protonation reaction coupled with the reduction process (Garrido et al. 2004). This is the commonly observed behavior for reduction of the $>C=C<$ group (Subbalakshmamma and Reddy 1994). The cathodic

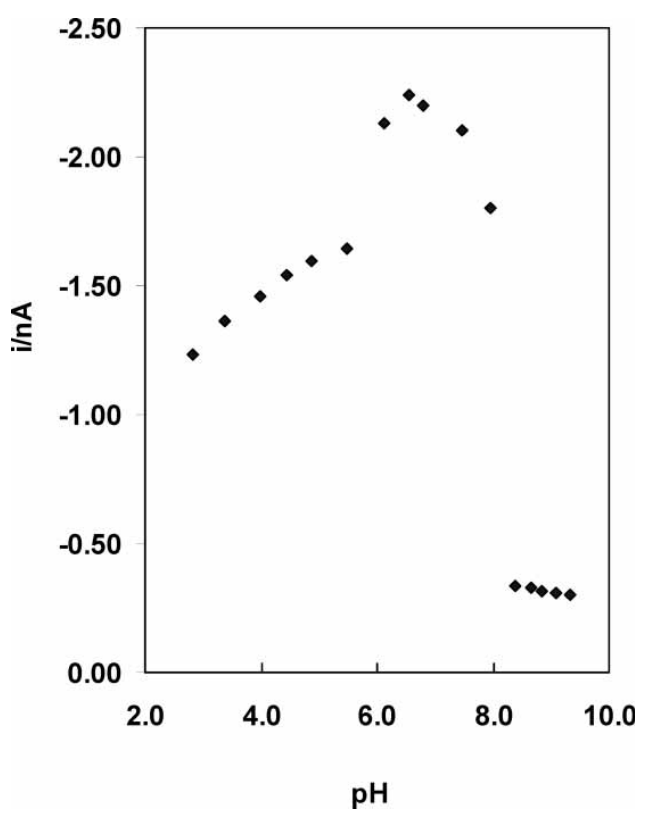

Figure 2. Effect of varying $\mathrm{pH}$ on the cathodic stripping peak current of chlorfenvinphos in a soil extract containing $4.0 \times 10^{-7} \mathrm{~mol} \mathrm{l}^{-1}$. Deposition during $10 \mathrm{~s}$ at $-0.60 \mathrm{~V}$. Frequency $=50 \mathrm{~Hz}$. 
response obtained at $\mathrm{pH} 6.2$ was well defined, had a peak potential at $\sim-1.2 \mathrm{~V}$ and was selected for further studies.

To get the more appropriate conditions for chlorfenvinphos detection at the MFU, the adsorptive square-wave voltammetric parameters were optimized. The marked dependence of the peak current of $4.0 \times 10^{-7} \mathrm{~mol} \mathrm{l}^{-1}$ chlorfenvinphos on the accumulation potential was evaluated over the range $-0.1--1.6 \mathrm{~V}$ (Fig. 3). A gradual increase in peak current intensity was observed between $-0.1 \mathrm{~V}$ and $-0.6 \mathrm{~V}$ starting to decrease in a roughly linear manner thereafter and reaching the lowest value at $-1.6 \mathrm{~V}$. The optimal preconcentration potential of $-0.60 \mathrm{~V}$ was chosen because the best peak shape and a maximum developed peak current were achieved at this potential. To improve the repeatability of the analytical response and to protect the MFU surface from fouling, a cleaning step consisting in applying a conditioning potential of $-1.6 \mathrm{~V}$ during $10 \mathrm{~s}$ was introduced in the electrochemical procedure and always performed before each new scan. Repetitive measurements cycles were carried out using a deposition time of $20 \mathrm{~s}$ and a frequency of $50 \mathrm{~Hz}$ in a soil extract containing $5.7 \times 10^{-8} \mathrm{~mol} \mathrm{l}^{-1}$ of chlorfenvinphos. The results of 50 successive measurements showed only $5.5 \%$ relative standard deviation $(0.310 \pm 0.017 \mathrm{nA})$ and no drift of the peak potential was observed.

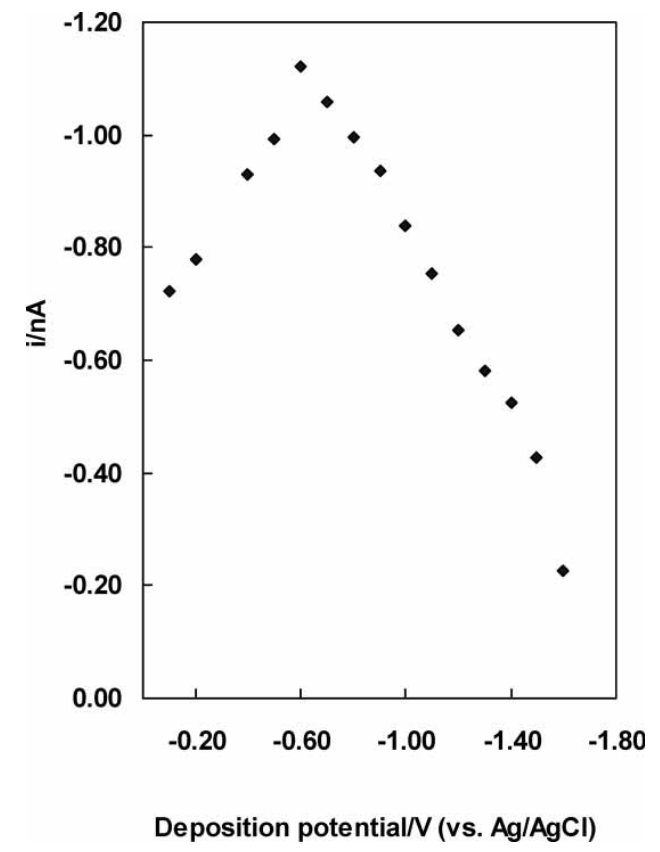

Figure 3. Effect of the deposition potential on the chlorfenvinphos peak current in a soil extract containing $2.0 \times 10^{-7} \mathrm{~mol}^{-1}$ after $10 \mathrm{~s}$ deposition. Frequency $=50 \mathrm{~Hz}$. 
In addition to the selection of the preconcentration potential, it is necessary to choose a suitable time for this step. The optimization of the deposition time in soil extracts containing different concentrations of chlorfenvinphos $\left(1.0 \times 10^{-7} \mathrm{~mol} \mathrm{l}^{-1}\right.$ and $\left.2.0 \times 10^{-7} \mathrm{~mol} \mathrm{l}^{-1}\right)$ demonstrated that initially the peak current increased linearly with time (between 0 and $60 \mathrm{~s}$ for the lowest concentration, $\mathrm{r}=0.999, n=9$; between 0 and $40 \mathrm{~s}$ for the other concentration, $\mathrm{r}=0.998, n=11$ ) but then the plot began to exhibit a change of slope commencing at approximately $40 \mathrm{~s}$ and $60 \mathrm{~s}$, respectively for $2.0 \times 10^{-7} \mathrm{~mol}^{-1}$ and $1.0 \times 10^{-7} \mathrm{~mol} \mathrm{l}^{-1}$, and subsequently leading to a flattening of the curve promoted by gradual saturation of the MFU surface. Considering these observations, $20 \mathrm{~s}$ was the maximum deposition time applied. Due to the inherent properties of ultramicroelectrodes, no forced convection during the deposition step and no equilibration period before the cathodic scan were used.

In order to obtain maximum sensitivity, the square-wave frequency, the scan increment and the pulse amplitude were examined, varying one of them and maintaining the others constant. The variable ranges studied were $10-300 \mathrm{~Hz}$ for the frequency $(n=18) ; 10-100 \mathrm{mV}$ for the amplitude $(n=10) ; 1-10 \mathrm{mV}$ for the scan increment $(n=10)$. The peak intensity and potential increase at higher frequency values, the slope of the baseline and peak width augment with the amplitude and higher scan increment values increased the peak height but resulted in peak distortion. The optimum parameters for the determination of chlorfenvinphos in soil extracts were established as a frequency $=250 \mathrm{~Hz}$, amplitude $=20 \mathrm{mV}$ and a staircase step $=3 \mathrm{mV}$.

\section{Voltammetric Analytical Characteristics and Application}

A type I soil extract containing $5.7 \times 10^{-8} \mathrm{~mol}^{-1}$ of chlorfenvinphos, the standard addition method was used to establish the linearity range (Fig. 4; the dotted line is the blank soil extract). With a $10 \mathrm{~s}$ deposition time, the peak height increased linearly (i $(\mathrm{A})=-7.49 \times 10^{-10}-1.35 \times 10^{-2}$ [chlorfenvinphos; $\left.\left.\mathrm{mol}^{-1}\right] ; \mathrm{r}=0.999 ; n=13\right)$ up to the twelfth standard addition of chlorfenvinphos (each of $5.0 \times 10^{-8} \mathrm{~mol} \mathrm{l}^{-1}$ ) that corresponded to a final concentration of $6.57 \times 10^{-7} \mathrm{~mol}^{-1}$ in the sample. When further standard additions were made, deviations from linearity became significant due to the saturation of the MFU. Interesting is to note that by using a deposition time of only a few seconds, working at an analytical concentration $5.7 \times 10^{-8} \mathrm{~mol} \mathrm{l}^{-1}$ is possible. This is a consequence of the very high flux of the electroactive species towards the microelectrode surface. The limit of detection (LOD) was calculated from the mean equation of the linear part of the plot, as recommended by IUPAC (Miller and Miller 1994), and a value of $3.0 \times 10^{-8} \mathrm{~mol}^{-1}$ was obtained. The proposed analytical method allows a detection limit of $0.042 \mu \mathrm{g} \mathrm{g}^{-1}$ in soils to be reached using a 


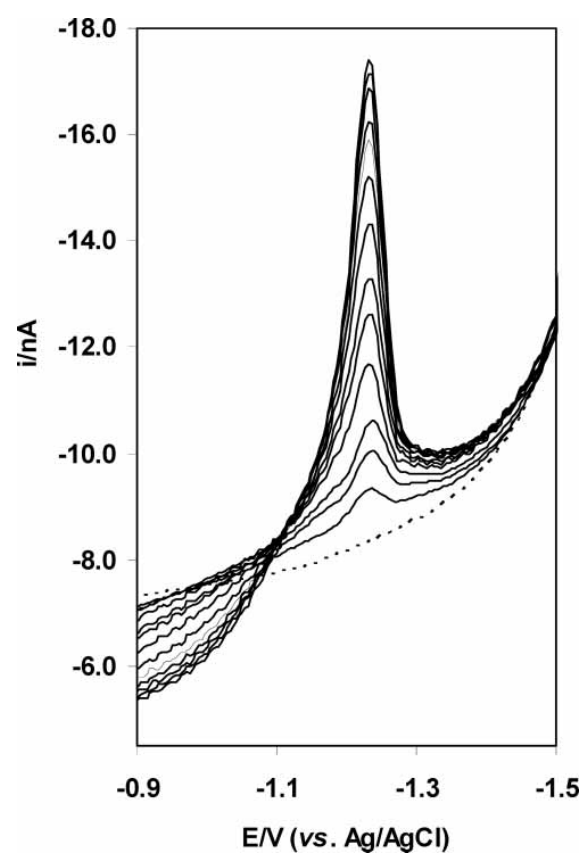

Figure 4. Voltammograms obtained after 12 successive chlorfenvinphos standard additions of $5.0 \times 10^{-8} \mathrm{~mol}^{-1}$ to a soil extract containing $5.7 \times 10^{-8} \mathrm{~mol}^{-1}$ for determining the linearity range. (---) in the blank soil extract. $10 \mathrm{~s}$ deposition at $-0.60 \mathrm{~V}$; frequency $=250 \mathrm{~Hz}$.

deposition time of only $10 \mathrm{~s}$. A significant improvement in LOD can be achieved by using a higher deposition time or/and redissolving the soil residues in a volume less than $20 \mathrm{ml}$ (the miniaturized dimension of the MFU offers the possibility to use small volumes of sample solution). Chlorfenvinphos is used either as a soil insecticide at $2-4 \mathrm{~kg} \mathrm{ha}^{-1}$ or as a foliar insecticide on potato, citrus or mushroom at $0.2-0.4 \mathrm{~g} \mathrm{ha}^{-1}$, and on maize, rice and sugarcane at 0.55-2.2 $\mathrm{g} \mathrm{ha}^{-1}$ (Tomlin 1997; http://www.eco-usa.net/toxics/ chlorfen.shtml). So the developed procedure allows detection of commonly applied doses of this compound in soils. Also, since chlorfenvinphos has been detected in foodstuffs (Tarbah et al. 2001) and that the sensitivity of the method is sufficient to enable testing of compliance with food regulations and maximum residue levels established in the EU (ranging from 0.01$3.0 \mu \mathrm{g} \mathrm{g}^{-1} \quad$ (http://www.europa.eu.int/comm/food/index_en.htm)) and USA (The Food and Drug Administration set tolerances for chlorfenvinphos for agricultural products ranging from $0.005-0.2 \mu \mathrm{g} \mathrm{g}^{-1}$ (http://www.ecousa.net/toxics/chlorfen.shtml)); another possible applicability of the proposed method is for monitoring vegetables and fruits after adequate optimization of the sample pretreatment. 
The analytical performance of the developed MASE-electrochemical procedure was assessed by applying it to the determination of chlorfenvinphos in the two soils having significantly different properties (type I and II). None of the natural samples analyzed contained detectable amounts of the insecticide (see a blank soil extract presented in Fig. 4), so they were spiked at the $0.1 \mu \mathrm{g} \mathrm{g}^{-1}$ level. After MASE, filtration of the supernatant, drying and redissolution of the residues with $20 \mathrm{ml}$ Britton-Robinson buffer $\mathrm{pH}=6.2$, each quantification was performed by three standard additions of $5.0 \times$ $10^{-8} \mathrm{~mol} \mathrm{l}^{-1}$ with three replicates at each concentration and using an accumulation time of $20 \mathrm{~s}$. The average recoveries and standard deviations for the global procedure reached by MASE-square-wave voltammetry were $90.2 \pm 2.8 \%$ and $92.1 \pm 3.4 \%$ for type I and type II soil samples, respectively. These results are in accordance to the expected values, which show that the method has a good accuracy. Nevertheless, it should be noted that the recovery for chlorfenvinphos contaminated soils might not be attained in the same extent to that of spiked samples since sorption strength increases with increasing residence time of the compound in soil. To our knowledge, there are no reports on the application of MASE combined with stripping voltammetry to the analysis of chlorfenvinphos in soils or in other matrices. This technique provides efficient enrichment and clean up, as well as, good selectivity, sensitivity and speed, with only minor production of laboratorial residues containing organic solvents. Furthermore, and in agreement with other reported studies (Baldo et al. 2002), the MFU displays a good stability which indicates the possibility of using the $\mathrm{Hg}$-Au ultramicroelectrode for a quite long period of time, would be beneficial for in situ studies since severe environmental problems can result from the persistence of chlorfenvinphos and other organophosphorus pesticides in soils and sediments, as well as their run-off to surface and ground waters. To attend EU legislation for drinking waters $\left(0.1 \mu \mathrm{g} \mathrm{l} \mathrm{l}^{-1}\right.$ is the maximum allowable concentration (http:// www.pan-uk.org/pestnews/pn22/pn22p10.htm), the developed methodology would require a preconcentration step before quantification.

\section{REFERENCES}

Baldo, M.A., Daniele, S., Bragato, C., and Mazzocchin, G.A. 2002. Voltammetric investigation on sulfide ions in aqueous solutions with mercury-coated platinum microelectrodes. Anal. Chim. Acta, 464: 217-227.

Bard, A. and Faulkner, L.R. 1980. Electrochemical Methods: Fundamentals and Applications; Wiley: New York.

El-Shahawi, M.S. and Kamal, M.M. 1998. Determination of the pesticide chlorpyrifos by cathodic adsorptive stripping voltammetry. Fresenius J. Anal Chem., 362: 344-347.

Eskilsson, C.S. and Bjorklund, E. 2000. Analytical-scale microwave-assisted extraction. J. Chromatography A, 902: 227-250. 
Garrido, E.M., Delerue-Matos, C., Lima, J.L.F.C., and Brett, A.M.O. 2004. Electrochemical methods in pesticides control. Anal. Lett., 37: 1755-1791.

Hesse, P.R. 1972. A Textbook of Soil Chemical Analysis; Chemical Publishing Co., Inc.: New York. http://www.eco-usa.net/toxics/chlorfen.shtml. http://www.europa.eu. int/comm/food/index_en.htm. http://www.pan-uk.org/pestnews/pn22/pn22p10. htm.

Jansson, C., Pihlstrom, T., Osterdahl, B.-G., and Markides, K.E. 2004. A new multiresidue method for analysis of pesticide residues in fruit and vegetables using liquid chromatography with tandem mass spectrometric detection. J. Chromatograhy A, 1023: 93-104.

Manisankar, P., Viswanathan, S., Pusphalatha, A.M., and Rani, C. 2005. Electrochemical studies and square-wave stripping voltammetry of five common pesticides on poly 3,4-ethylenedioxythiophene modified wall-jet electrode. Anal. Chim. Acta, 528: $157-163$.

Manzanilla-Cano, J.A., Barceló-Quintal, M.H., Reyes-Salas, E.O., and FloresRodríguez, J. 2001. Electrochemical behavior of methylparathion Ander UV irradiation. Intern. J. Environ. Anal. Chem., 80: 115-127.

Miller, J.C. and Miller, J.N. 1994. Statistics for Analytical Chemistry; Ellis-Howood: New York.

Mongay, C.F. and Martín, V.C. 1977. Preparation d'un tampon universal de force ionique $0.3 \mathrm{M}$. Talanta, 24: 747-748.

Montenegro, MI., Queiros, M.A., and Daschbach, J.L. 1991. Microelectrodes: Theory and Applications; Kluwer Academic Publishers: Dordrecht, Amsterdam.

Morais, S. and Pereira, M.C. 2000. Application of stripping voltammetry and microelectrodes to in vitro biocompatibility and in vivo toxicity tests of AISI 316L corrosion products. J. Trace Elements Biol., 14: 48-54.

Morais, S., Ryckaert, C.P.M.C.A., and Delerue-Matos, C. 2003. Adsorptive stripping voltammetric determination of venlafaxine in urine with a mercury film microelectrode. Anal. Letters, 36: 2515-2526.

Morais, S., Tavares, O., and Matos, C. 2005. Voltammetric determination of dialifos in soils with a mercury film ultramicroelectrode. Anal. Letters, 38: 1275-1288.

Ni, Y., Qiu, P., and Kokot, S. 2004. Simultaneous determination of three organophosphorus pesticides by differential pulse stripping voltammetry and chemometrics. Anal. Chim. Acta, 516: 7-17.

Russo, M.V., Campanella, L., and Avino, P. 2002. Determination of organophosphorus pesticides residues in human tissues by capillary gas chromatography-negative chemical ionization mass spectrometry analysis. J. Chromatograhy B, 780: $431-441$.

Subbalakshmamma, M. and Reddy, S.J. 1994. Electrochemical reduction behaviour and analysis of some organophosphorous pesticides. Electroanalysis, 6: 521-526.

Tarbah, F.A., Mahler, H., Temme, O., and Daldrup, T. 2001. An analytical method for the rapid screening of organophosphate pesticides in human biological samples and foodstuffs. Forensic Sci. Int., 121: 126-133.

Tomlin, C.D.S. 1997. The Pesticide Manual, 11th Ed.; British Crop Protection Council: Surry, UK.

United Status Environmental Protection Agency (USEPA). 1994. Method 8141 A Organophosphorus Compounds by Gas Chromatography: Capillary Column Technique Washington, DC: US Government Printing Office.

Uygun, U. 1997. Degradation of chlorfenvinphos in carrots during storage. Food Chem., 60: 479-487. 